\title{
Eco friendly service buildings and facilities for sustainable tourism and environmental awareness in protected areas
}

\author{
D. Astiaso Garcia ${ }^{1}$, F. Cumo ${ }^{2}$, V. Sforzini ${ }^{3} \&$ A. Albo ${ }^{1}$ \\ ${ }^{I}$ DIAEE, Department of Astronautical, Electrical and Energy \\ Engineering, Sapienza University of Rome, Italy \\ ${ }^{2}$ CITERA, Inter-department Centre for Territory, Building, \\ Conservation and Environment, Sapienza University of Rome, Italy \\ ${ }^{3}$ Department of Energy and Environment, \\ Guglielmo Marconi Telematic University of Rome, Italy
}

\begin{abstract}
Starting from the multi-year experience in environmentally friendly building projects gained by CITERA of the Faculty of Architecture (Sapienza University of Rome), the main goal of this paper is to apply this expertise for the planning of environmentally sound service buildings and facilities in natural protected areas, in order to increase tourist facilities avoiding the subsequent environmental impacts that too often are produced in areas with high environmental and landscaping values. Therefore, this paper will take into account the relationships between service buildings for tourism and their eventual ecological impacts in the surrounding areas, in order to pinpoint innovative envelope technologies as well as technical smart solutions for a sustainable promotion of tourist facilities, including, in addition to service buildings, even the requalification of paths and water routes. The other central aim of the project is to propose practical methods for the use of these service buildings and facilities as favourable places to disseminate environmental protection notions. Furthermore, the project foresees the application of a case study in the Bracciano-Martignano Regional Park. The obtained results may be used by other protected areas administrations as possible solutions for improving environmental sustainability of their tourism management plans.
\end{abstract}

Keywords: energetically self supported buildings, high-tech polymeric additives. 


\section{Introduction}

Ecosystems provides human populations with a number of services and goods, generally called ecosystem services, defined by "Nature" International Journal of Science as "the benefit human populations derive, either directly or indirectly, from ecosystem functions" [1].

On the other hand, human presence modifies both the biotic and the abiotic properties of natural ecosystems. This mainly through land-use changes; habitat fragmentation [2]; depletion of natural resources; alterations on carbon; nutrient and water flows; light [3] and noise [4] pollution levels; increase of air and soil temperatures; as well as release of wastes and emissions in water, atmosphere and soil with the consistent alteration of nutrient content and $\mathrm{pH}$ levels.

According with the Siracusa Environment Ministers Meeting of the G8 countries [5], the direct destruction of ecosystems, fragmentation of natural spaces, disturbance to species, introduction of alien species, pollution, and urban heat islands are the major threats to biodiversity.

An incorrect tourist facilities planning may involve all these main impacts. Actually, considering that two of the main challenges of our century are loss of biodiversity and climate change [6], it is obvious to understand how significant it is to plan efficient strategies, to achieve good standards of ecological sustainability in protected areas [7].

In the light of the above mentioned considerations, the main goal of this paper is to briefly introduce some practical solutions and strategies that are able to influence the environmental performance of tourism, in order to design conservation planning strategies that increase sustainability and mitigate the ecological and environmental impacts of tourist facilities, especially in countries like the European ones where human population density is usually particularly high.

Sustainable tourism can be defined as "Tourism that takes full account of its current and future economic, social and environmental impacts, addressing the needs of visitors, the industry, the environment and host communities" [8].

However, since any definition of sustainability should contain long-term benefits both to human well-being and to biodiversity conservation, this paper would present in a very short way the main aspects nowadays related to ecological sustainability and low-impact tourism facilities.

Moreover, considering that effective public awareness strategies are essential for the achievement of the main environmental targets recognized by the major international organisations, it will be highlighted how crucial is to sensitise tourists on their responsibility to use with care environmental resources avoiding habitats degradation.

\section{Environmentally sound tourist facilities in protected areas}

In order to achieve environmental conservation and ecological sustainability in the design of buildings and facilities, the mains strategies make use of 
intervention of ecological engineering, ecological design architecture and sustainable bio-architecture [9] based on resource-efficient technologies [10]. These designs often foresee also the use of innovative materials for foot and cycle paths.

\subsection{Eco friendly service buildings and green architecture designs}

One of the main objectives of CITERA is to improve environmental sustainability and life quality. In particular, considering strategies for sustainable tourism, CITERA has applied its multi-year experience in environmentally friendly building projects for planning small sustainable bungalows (about 15$20 \mathrm{~m}^{2}$ ) that can offer same services for tourists (toilette, information screen, restoration desk, etc) minimizing environmental impacts and increasing environmental awareness of visitors [11].

These low-impact bungalows have been designed for touristic wilderness areas, where the conservation of the surrounding natural and landscaping values is required.

Briefly these constructions have no foundations, are realized with ecomaterials (usually prefabricated wood elements), and are completely energetically self supported, thanks to a stand-alone photovoltaic plant of about $1-1.5 \mathrm{kWp}$ integrated on the roof.

\subsection{Innovative technologies for low impact paths}

Supporting accessible and liveable green spaces on the one hand is generally considered of utmost importance also for environmental public awareness, while, on the other hand, may generate disturbance and impacts on natural environments and wild species populations we would like to conserve.

Consequentially, one of the main challenges for tourism facilities planning is to plan strategies and interventions trying to find an effective compromise between these two considerations, in order to promote both accessibility and amenity places.

In order to increase sustainability and, at the same time, to allow access of natural places on foot or by bicycle, a careful analysis of ecological and hydrogeological aspects of a natural protected area should precede the fulfilment of cycle or foot paths for tourists.

In particular, it is of utmost importance the safeguard of the hydraulic and hydrogeological systems. Indeed, the construction of impermeable paths in natural areas causes the decrease of water infiltration and the subsequent increase of surface runoff. When the flow of surface runoff crosses a certain threshold, the slopes are eroded by water and may occur a hydro geological instability, with potential consequences on natural ecosystems and visitors.

In order to avoid these dangerous situations for safety and ecosystems conservation, we have planned the use of drain materials for the realization of foot or cycle paths in natural protected areas. 
Furthermore, for mitigating environmental impacts, the drainage of paths can be constructed by a mix of high-tech polymeric additives, mineral aggregates and hydraulic blinder. We have foreseen the use of specific polymeric additives that are hydro soluble, non toxic and environmental neutral.

In particular, an example for the realization of low impact paths is the following: the first layer of finished path is composed by a water permeable paving, then there is a drain layer composed by a mix high-tech polymeric additive, mineral aggregate and hydraulic blinder. At the bottom, there is bedrock (figure 1).

In this way, the drain layer stores the infiltration and allows water to seep through the bed-rock.

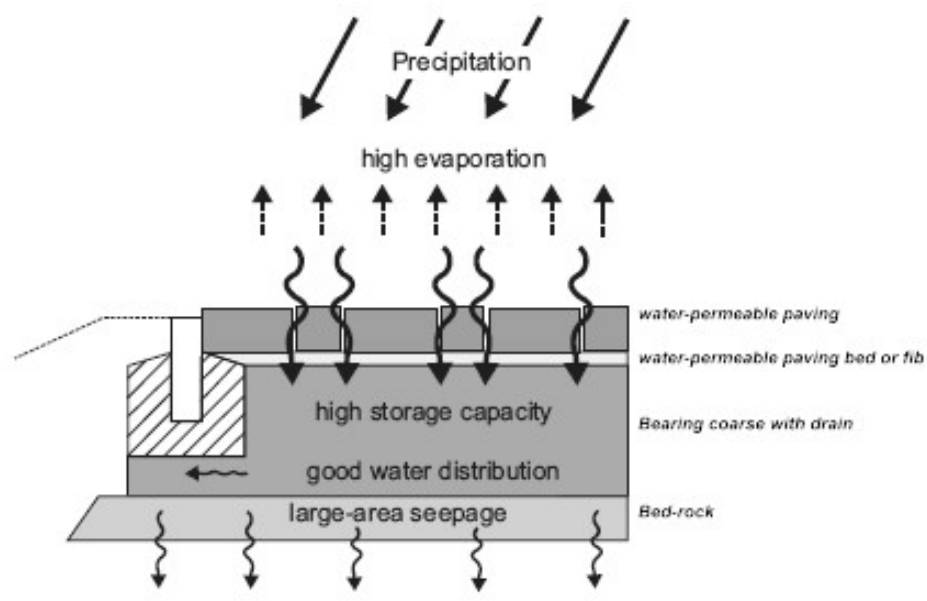

Figure 1: $\quad$ Section of low-impact path for tourists.

Moreover, these strategies for foot and cycle paths help biodiversity conservation thanks to the maintenance of the ecological corridors that can usually promote gene flow between isolating populations mitigating effects of habitat fragmentation, ensuring the necessary genetic shuffling between neighbouring populations of the same species and consequentially avoiding inbreeding depression and lowering of population size until MVP (Minimum Viable Population) [12].

\section{Strategies for environmental awareness in protected areas}

It is of utmost importance for biodiversity conservation to promote the experience of people with nature, as well as to analyse their damage perception of environmental critical aspects for improving personal interactions with surrounding nature [13]. 
In this light, tourism have the potential power of bringing nature into the mindset of citizens, offering to them the possibility of appreciate the multiple values of nature.

In addition, conventional wisdom interrelates conservation of nature with interventions on wild and uncontaminated areas.

On the other hand, natural touristic places play also a rule of dissemination in the global battle to halt the loss of biodiversity, given that they represent an important contact between citizens and nature. These contacts are essential to sensitise public awareness on environmental issues, helping citizens to "think globally and act locally" for safeguarding the areas where they live and for supporting or financing nature conservation activities [14].

The dissemination of sustainability best practices as well as planning of strategies for increasing environmental public awareness, with particular regards to the education of future generations, should be part of any plan for tourism management in a natural protected area. In fact, nowadays it is no longer possible that only few experts know what it is happening in our surrounding environments, but for the protection of resources of everyone, it needs the support of everyone.

These long-term strategies aim to achieve in everyone a sort of environmental citizenship that will allow a widespread social background of common responsibilities and benefits.

\section{The case study of the Italian Regional Park of Bracciano Martignano}

In order to test the real effectiveness of the research outputs, our project foresees the application of a case study in the Bracciano-Martignano Regional Park, with particular regard to the municipality of Trevignano, that received by the Italian Touring Club the "Bandiera Arancione" (Orange Flag) recognition (listed by the World Tourism Organization) for its high quality of tourism management.

Moreover, this area is included in a SCI (Site of Community Importance) "Lago di Bracciano - IT6030010" and a SPA (Special Protected Area) "Comprensorio Bracciano-Martignano - IT6030085" of the Natura 2000 Ecological Network of the European Union.

Considering tourism, these natural areas are visited year-round, mainly for their short distance from the city of Rome.

In particular CITERA has planned three different typologies of intervention for increasing sustainability of touristic facilities.

First of all the realization of some low impact infopoints, designed according with the standards described in paragraph 2.1.

These infopoints will be located along the cycle or foot paths of the Regional Parks (figure 2), providing services to tourists and, at the same time, increasing their environmental awareness trough informative panels with information about the natural and landscaping heritage of the area. 


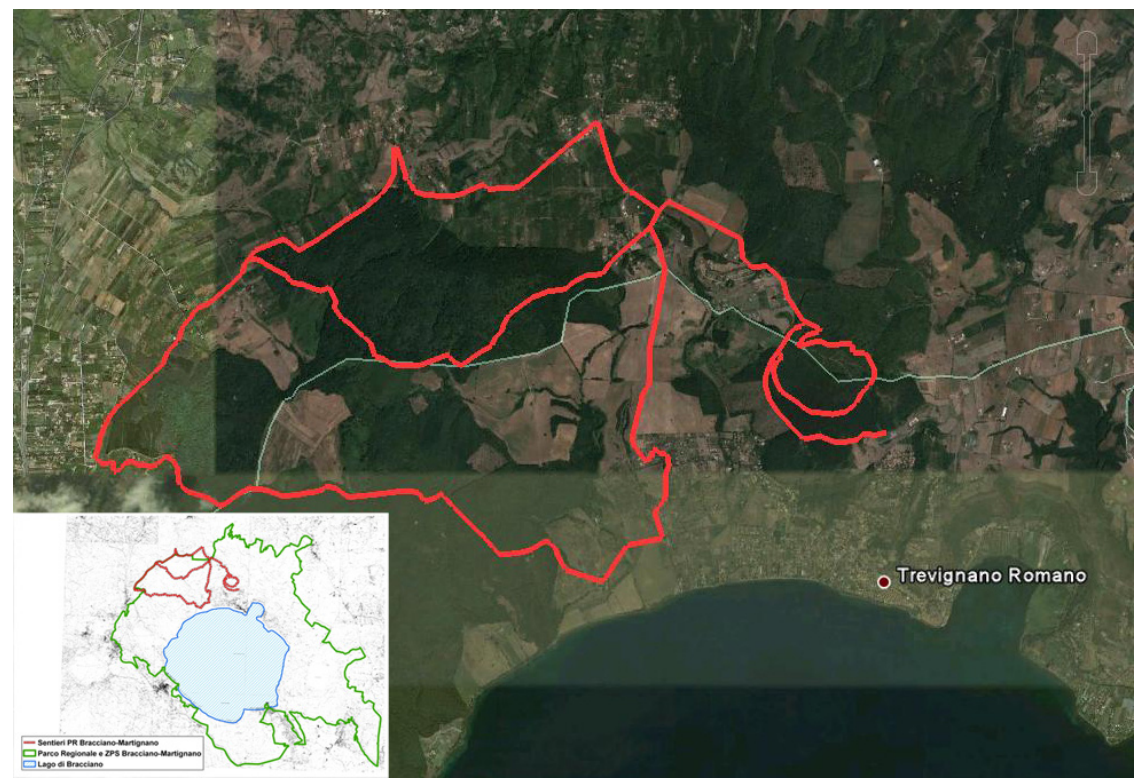

Figure 2: Cycle and foot paths of the municipality of Trevignano Romano.

The second typology of intervention concerns the application of the innovative technologies described in paragraph 2.2 for the requalification of the cycle and foot paths of the regional Parks (figure 3 ).
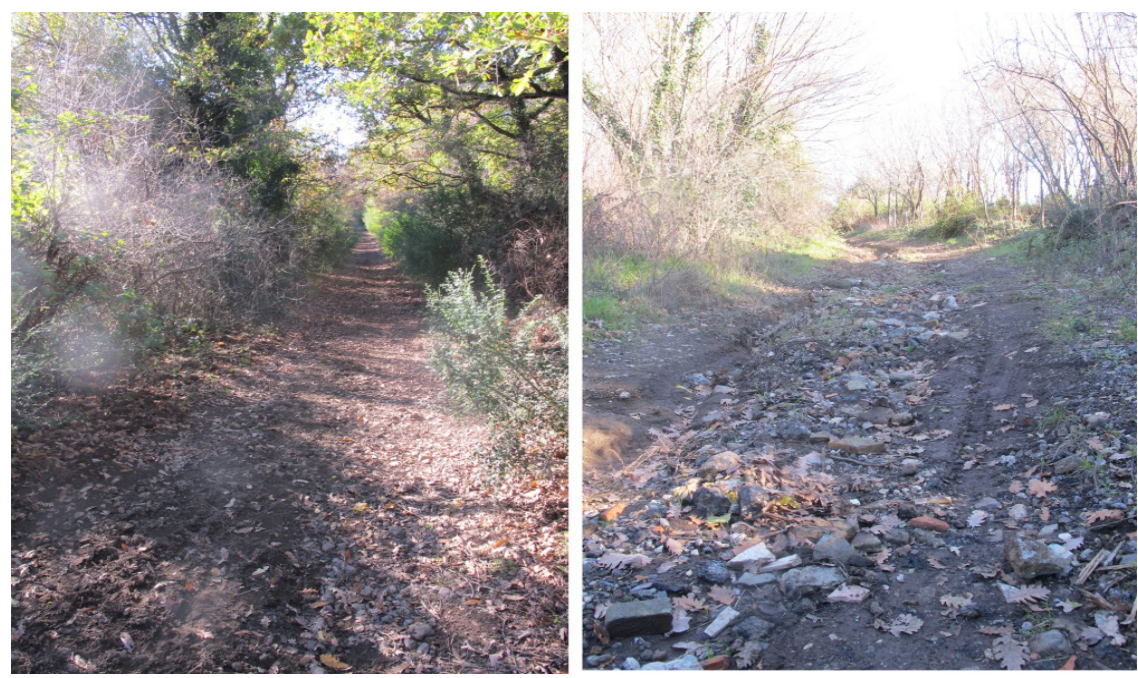

Figure 3: Cycle and foot paths of the Bracciano - Martignano Regional Park before interventions with environmentally neutral nanoparticles. 
Moreover, in order to reduce road traffic and greenhouse gas emissions CITERA designed an electrically powered boat equipped with an electrical device built into the roof of the building. This mini-cruise service will create an eco friendly connection for tourists and citizens between the village of Trevignano Romano and the surrounding beaches of the Bracciano Lake.

\section{Conclusions}

In the light of the brief analysis and considerations of the above paragraphs, it is evidently clear that tourism sustainability is not a matter of rules or solutions that are effective in any circumstance. The real challenge is to find the best solution for any peculiar social, economic, natural and cultural context in which an intervention is required. It is of utmost importance to concentrate the efforts on the most effective strategies that nowadays certainly include a lot more scientific research and public awareness on environmental issues.

In fact, since each single ecosystem responds to human impacts with different mechanisms, in order to evaluate the real environmental impact of tourist activities on an area, we have to analyse and estimate the resilience of the ecosystems included in that zone. This means first to evaluate the amount of disturbance that they could adsorb without changing their main structure and functions; and then to plan environmentally friendly tourist facilities for minimizing their effective disturbance.

\section{References}

[1] Costanza R., d'Arge R., deGroot R., et al., 1997. The value of the world's eco system services and natural capital. Nature, 387, 253-60.

[2] Di Giulio M., Holderegger R. and Tobias S., 2009. Effects of habitat and landscape fragmentation on humans and biodiversity in densely populated landscapes. Journal of Environmental Management, 90, 2959-68.

[3] Small C., Pozzi F., and Elvidge C.D., 2005. Spatial analysis of global urban extent from DMSP-OLS night lights. Remote Sensing of Environment, 96, 277-91.

[4] Warren P.S., Katti M., Ermann M. and Brazel A., 2006. Urban bioacoustics: it's not just noise. Animal Behaviour, 71, 491-502.

[5] Environment Ministers of the G8 countries, 2009. Biodiversity: a new perspective. Guidelines for the discussion for Session III. Siracusa Environment Ministers Meeting, April, 23rd, 2009, 8 pp.

[6] Gill S.E., Handley J., Ennos A.R. and Pauleit S., 2007. Adapting cities for climate change: the role of green infrastructure. Built Environment, 33, 115-33.

[7] Astiaso Garcia D., 2011. Ecological sustainability of urban areas. In: F. Cumo, 2011. SoURCE Sustainable Urban Cells. Pp 103-113. Palombi Editore, 2011. 
[8] United Nations World Tourism Organization (UNWTO), Making Tourism More Sustainable: a guide for policy makers, Madrid: United Nations World Tourism Organization, 2004.

[9] Cumo F. and Di Matteo U., 2010. Bioarchitettura. Esperienze di ricerca progettuale in aree di pregio. Roma, Ugo Quintily, vol. 1.

[10] Cinquepalmi F., Gugliermetti F., Cumo F., Astiaso Garcia D., Calcagnini L. and Foglia M.L., 2008. Advanced technologies for sustainable building in the protected areas: the pilot project of the Municipality of Rome. Palombi and Partner, Rome, $8 \mathrm{pp}$.

[11] Cinquepalmi F., Cumo F., Gugliermetti F. and Sforzini V., 2010. Advanced technologies for sustainable building in the protected areas: two case studies in Italy. In: Eco-Architecture III Harmonisation. vol. 128.

[12] Gilpin M.E., Soulé M.E., 1986. Minimum Viable Populations: Processes of Species Extinction. In M.E. Soulé. Conservation Biology: The Science of Scarcity and Diversity. Sinauer, Sunderland, Mass. pp. 19-34.

[13] Dunn R.R., Gavin M.C., Sanchez M.C. and Solomon J.N., 2006. The pigeon paradox: dependence of global conservation on urban nature. Conservation Biology, 20, 1814-16.

[14] Sundseth k. and Raeymaekers G., 2006. Biodiversity and Natura 2000 in urban areas. Nature in Cities across Europe: A Review of Key Issues and Experience. Bruxelles Environment-IBGE/Leefmileu Brussel_BIM, Brussels. 